\title{
Qualidade de cozimento de massas de trigo e soja pré-cozidas por extrusão
}

\author{
Myriam Ferreira de Oliveira(1), Sin-Huei Wang(1), Priscila de Souza Costa ${ }^{(1)}$ \\ e José Luis Ramírez Ascheri(2)
}

\begin{abstract}
(1)Universidade Federal Rural do Rio de Janeiro, Dep. de Economia Doméstica, BR 465, Km 47, CEP 23890-000 Seropédica, RJ. E-mail: myriamfo@yahoo.com.br, sin-hueiwang@bol.com.br, social.girl@globo.com (2)Embrapa Tecnologia Agroindustrial de Alimentos, Av.das Américas, 29501, CEP 23020-470 Guaratiba, RJ. E-mail: ascheri@ctaa.embrapa.br
\end{abstract}

\begin{abstract}
Resumo - O objetivo deste trabalho foi avaliar os efeitos da temperatura de barril (TB) do extrusor e o nível de umidade da mistura de trigo e soja na qualidade de cozimento de massas pré-cozidas por extrusão. Usou-se extrusor Brabender de rosca única com velocidade de alimentação constante de $3,6 \mathrm{~kg} / \mathrm{h}$, velocidade da rotação de parafuso de $90 \mathrm{rpm}$ e uma matriz de lâmina com $1 \mathrm{~mm}$ de espessura. Os resultados mostraram que, com as crescentes proporções de soja (10\% a 40\%), houve aumento das perdas de sólidos solúveis no tempo ótimo de cozimento. As perdas diminuíram com a elevação da TB até um mínimo, além do qual, aumentaram. $\mathrm{O}$ aumento de umidade diminuiu as perdas nas TB mais baixas, porém aumentou as perdas nas TB mais altas, as quais foram afetadas pela proporção de soja. A elevação da TB causou uma diminuição no aumento de peso e de volume até um mínimo, além do qual, houve aumento. Houve redução no aumento de peso e de volume no tempo ótimo de cozimento com o aumento de umidade e da proporção de soja.
\end{abstract}

Termos para indexação: massa extrusada, mistura de trigo e soja, perdas por cozimento.

\section{Cooking quality of pre-cooked wheat-soybean pastas by extrusion}

\begin{abstract}
The objective of this work was to evaluate effects of barrel temperature (BT) of extruder and moisture levels of wheat and soybean mixture on cooking quality of pre-cooked pastas by extrusion-cooking. The experiment was carried out, using Brabender single screw extruder with a constant feeding rate of $3.6 \mathrm{~kg} / \mathrm{h}$, a constant screw-speed of $90 \mathrm{rpm}$ and a laminar shape die of $1 \mathrm{~mm}$. Results showed that the soluble solid losses at an optimum cooking time increased with increasing soybean proportions ( $10 \%$ to $40 \%$ ). The losses decreased with increasing BT up to a minimum, beyond which they increased. The moisture increase caused decreased losses at lower BT, however, an increase occurred at higher BT, which was affected by soybean proportions. Increasing BT caused a decrease in increased cooked weight and cooked volume up to a minimum, beyond which it increased. A reduction in increased cooked weight and cooked volume at optimum cooking time with the moisture increase and soybean proportion increase was verified.
\end{abstract}

Index terms: extruded pasta, mixture of wheat and soybean, cooking losses.

\section{Introdução}

O consumo de massa alimentícia vem se expandindo no Brasil. Algumas das razões do crescimento da demanda e conseqüiente maior produção industrial são o custo relativamente baixo do produto e a facilidade de preparo (Leitão et al., 1989).

A massa produzida a partir da farinha de trigo, possui alto valor calórico, mas apresenta baixa qualidade protéica, em virtude da deficiência em lisina e do baixo conteúdo de proteína de trigo. A adição de soja à massa resulta na melhoria da qualidade protéica, por meio da complementação mútua de aminoácidos e do aumento no teor de proteínas totais (Gonzalez-Agramon \& SernaSaldivar, 1988; Caballero-Córdoba et al., 1994).

A qualidade da massa depende das características de suas matérias-primas e das condições de processamento e secagem. A secagem é a etapa que exige maior controle durante o processo de fabricação, pois pode afetar não só a preservação mas também a qualidade do produto (Leitão et al., 1989). Industrialmente, o processo convencional de secagem utiliza baixa temperatura, porém é demorado, o que limita a expansão da produção industrial. Leitão et al. (1989), De Stefanis \& Sgrulletta (1990) e Grant et al. (1993) utilizaram altas temperaturas na secagem da massa e veri- 
ficaram que esse processo reduziu o tempo de secagem e melhorou a qualidade de cozimento do produto, ao comparar com o método convencional de baixas temperaturas. Apesar das vantagens apresentadas pela secagem em alta temperatura, esse processo ainda é considerado lento. Assim o processo de extrusão pode ser uma possível solução para minimizar esse problema, embora a maioria das informações sobre a massa extrusada tenham surgido somente na forma de patentes.

Além de apresentar benefícios de um processo térmico convencional, o processo de extrusão é rápido e oferece as possibilidades de modificar estruturas do amido e proteínas, tais como: gelatinização e fragmentação do amido, desnaturação de proteínas e interações entre seus produtos (Cheftel et al., 1989; Horváth et al., 1989). Estas modificações podem também melhorar as propriedades sensoriais (Chen et al., 1991). Portanto, infere-se que o processo de extrusão pode ser útil na obtenção de massas pré-cozidas de trigo e soja.

O objetivo deste trabalho foi estudar os efeitos da temperatura de barril do extrusor e o nível de umidade da mistura de trigo e soja na qualidade de cozimento de massas alimentícias pré-cozidas por extrusão.

\section{Material e Métodos}

As matérias-primas usadas foram a farinha de trigo, adquirida no comércio, e grãos de soja [Glycine max (L.) Merril], cultivar BRS-156, da safra de 2002, fornecidos pela Embrapa Soja, Londrina, PR.

A obtenção da massa pré-cozida e todas as análises físico-químicas foram feitas em duplicata.

$\mathrm{Na}$ farinha de trigo, nos grãos de soja integrais e decorticados e nas farinhas mistas cruas de trigo e soja, foram realizadas análises de umidade, extrato etéreo, proteína bruta e cinzas, segundo métodos preconizados pela American Association of Cereal Chemists (1995), e de fibra bruta, conforme Kamer \& Ginkel (1952).

Os grãos de soja foram decorticados e branqueados, conforme Wang et al. (2001). Em seguida, foram misturados com a farinha de trigo nas proporções de 10:90, 20:80, 30:70 e 40:60, em base seca, sendo acrescentada a água em diferentes níveis e as misturas desintegradas num moinho de facas e martelos com peneira de $2 \mathrm{~mm}$, obtendo-se farinhas mistas cruas de trigo e soja (90:10, 80:20, 70:30 e 60:40) com diferentes níveis de umidade. Essas farinhas foram extrusadas em extrusor Brabender de rosca única, usando-se velocidade de alimentação constante de $3,6 \mathrm{~kg} / \mathrm{h}$, uma velocidade da rotação de parafuso (№ 2) de 90 rpm e uma matriz de lâmina com espessura de $1 \mathrm{~mm}$. Os perfis de temperatura de barril (TB) do extrusor foram: zona $1,50^{\circ} \mathrm{C}$ (constante); zonas 2 e $3,70,80,90$ e $100^{\circ} \mathrm{C}$. As massas pré-cozidas por extrusão foram designadas nas seguintes seqüências: Grupo I, com $10 \%$ de soja, em três níveis de umidade, 23, 26 e $29 \%$; Grupo II, com $20 \%$ de soja, em três níveis de umidade, 26, 29 e 32\%; Grupo III, com 30\% de soja, em três níveis de umidade, 29,32 e $35 \%$, e Grupo IV, com $40 \%$ de soja, em três níveis de umidade, 32,35 e $38 \%$. Em seguida, as massas extrusadas foram secadas em estufa a $50^{\circ} \mathrm{C}$ com circulação de ar por 1 hora, até a umidade de aproximadamente 9-10\%, sendo submetidas às subseqüientes análises. Foram usadas como controle massas de duas marcas comerciais, GCA e GCB.

Na determinação da qualidade de cozimento da massa pré-cozida, $5 \mathrm{~g}$ de cada uma foram cozidas em $200 \mathrm{~mL}$ de água destilada fervente, segundo o método de Kruger et al. (1994). O tempo ideal de cozimento foi determinado mediante a colocação da massa seca em água fervente, removendo a amostra em intervalos de $1 \mathrm{~min}$ e esmagando-a entre duas placas de vidro. O tempo ideal de cozimento foi definido como sendo o tempo no qual a região opaca das tiras da massa desaparecesse. As massas cozidas na proporção de 1:10 em água sem sal e no tempo ideal e nos tempos de $1 \mathrm{~min}$, antes e depois daquele estabelecido como ideal, foram drenadas e esfriadas na água destilada por $1 \mathrm{~min}$, sendo drenadas novamente e armazenadas em recipiente hermeticamente fechado a $25^{\circ} \mathrm{C}$ por $10 \mathrm{~min}$. A seguir procedeu-se à análise sensorial realizada mediante o teste de ordenação pela preferência com 20 provadores, a fim de que fosse verificado o tempo ótimo de cozimento. O peso de cada massa cozida no tempo ótimo e suas perdas de sólidos solúveis durante o cozimento foram determinados em $10 \mathrm{~g}$ de massa cozida em $100 \mathrm{~mL}$ de água destilada fervente em seu respectivo tempo ótimo de cozimento, de acordo com o método de Dexter \& Matsuo (1979). Foi também calculado o aumento de peso e de volume das massas cozidas.

Os tratamentos para a determinação da qualidade de cozimento, foram distribuídos em delineamento inteiramente casualizado. Os dados foram submetidos à análise de variância e as médias comparadas pelo teste de Tukey a 5\% de probabilidade. As análises estatísticas foram realizadas conforme Pimentel-Gomes (1991). 
No teste de ordenação pela preferência, foi aplicada a tabela preconizada por Kramer citado por Kahan et al. (1973).

\section{Resultados e Discussão}

A composição centesimal aproximada obtida da farinha de trigo foi semelhante à encontrada por Leitão et al. (1989) (Tabela 1). A soja apresentou maiores teores de proteína bruta, extrato etéreo, cinzas e fibra bruta do que a farinha de trigo. $O$ teor de cinzas dos grãos de soja decorticados foi semelhante e os teores de proteína bruta e extrato etéreo maiores do que aqueles dos grãos de soja integrais. O alto teor de fibra bruta da soja integral indica que o tegumento (casca) contém grande quantidade deste componente. Resultados semelhantes foram verificados por Fernandes et al. (2002), mas com valores de proteína bruta, fibra bruta e carboidratos ligeiramente inferiores e valores de extrato etéreo e cinzas ligeiramente superiores aos deste trabalho, o que se deve, provavelmente, à diferença quanto a cultivar utilizada e condições edofoclimáticas. Por sua vez, a farinha de trigo apresentou maior teor de carboidratos, o que era esperado, pois a soja não contém amido. Por isso, os teores de proteína bruta, extrato etéreo, cinzas e fibra bruta aumentaram, ao passo que o porcentual de carboidratos diminuiu com maior proporção de soja (10\% a 40\%) nas farinhas mistas cruas de trigo e soja. Os resultados da composição centesimal aproximada da farinha mista crua de trigo e soja (Tabela 1) são semelhantes aos de Gonzalez-Agramon \& Serna-Saldivar (1988).

A elevação do nível de umidade da farinha mista crua e da temperatura de barril (TB) do extrusor resultou na diminuição do tempo ótimo de cozimento das massas pré-cozidas de trigo e soja em diferentes proporções por extrusão (Tabela 2). Quanto às massas de trigo (controle) de duas marcas comerciais, necessitou-se de tempo maior de cozimento. Taha (1992) também constatou que a redução do tempo de cozimento por causa da adição da farinha de soja foi mais significativa em níveis mais altos.

As perdas de sólidos solúveis no tempo ótimo de cozimento das massas de trigo e soja pré-cozidas por extrusão diminuíram com a elevação da TB até um valor mínimo, além do qual, essas perdas aumentaram (Tabela 3). Na proporção de $10 \%$ de soja, a elevação do nível de umidade diminuiu as perdas de sólidos solúveis nas TB de 70 e $80^{\circ} \mathrm{C}$, porém aumentou nas TB de 90 e $100^{\circ} \mathrm{C}$. Na proporção de $20 \%$ de soja, a diminuição de perdas com a elevação do nível de umidade foi verificada nas TB de 70,80 e $90^{\circ} \mathrm{C}$, porém o aumento dessas perdas ocorreu na TB de $100^{\circ} \mathrm{C}$. De modo diferente, nas proporções de 30 e $40 \%$ de soja, houve diminuição de perdas em função da elevação do nível de umidade nas TB de 70 e $80^{\circ} \mathrm{C}$, enquanto na TB de $90^{\circ} \mathrm{C}$, ocorreu uma diminuição e em seguida um aumento, já na TB de $100^{\circ} \mathrm{C}$, houve apenas aumento. Também ocorreu um aumento nas perdas de sólidos solúveis no tempo ótimo de cozimento quando se elevou a proporção de soja.

Dexter \& Matsuo (1979), Edwards et al. (1993) e Grant et al. (1993) relataram que as perdas de sólidos solúveis foram maiores, à medida que se aumentou o tempo de cozimento das massas. No caso de massas fortificadas com farinha de soja, Taha (1992) verificou que houve maiores perdas de sólidos solúveis, apesar de ter ocorrido uma redução no tempo de cozimento.

Segundo Edwards et al. (1993), além do tempo de cozimento, o conteúdo de proteína pode também afetar as perdas de sólidos solúveis. Dexter \& Matsuo (1979) verificaram que a qualidade superior de cozimento da massa do tipo espaguete pode estar relacionada com a proporção de proteína insolúvel no espaguete cozido, pois de acordo com esses autores, ocorreu uma rápida diminuição de proteínas sal-solúveis (albuminas e globulinas) e de proteínas glúten-solúveis (gliadina e gluteninas-solúveis) até cerca de 12 minutos de cozimento, com concomitante elevação do teor de proteínas insolúveis.

Tabela 1. Composição da farinha de trigo, dos grãos de soja integrais e decorticados, e das farinhas mistas cruas de trigo e soja.

\begin{tabular}{|c|c|c|c|c|c|c|c|}
\hline \multirow[t]{2}{*}{ Composição em base seca (\%) } & \multirow[t]{2}{*}{ Farinha de trigo } & \multirow[t]{2}{*}{ Soja integral } & \multirow[t]{2}{*}{ Soja decorticada } & \multicolumn{4}{|c|}{ Farinha mista crua de trigo e soja } \\
\hline & & & & $90: 10$ & $80: 20$ & $70: 30$ & $60: 40$ \\
\hline Proteína bruta & 13,06 & 42,04 & 45,90 & 16,08 & 19,29 & 22,84 & 26,44 \\
\hline Extrato etéreo & 1,25 & 18,63 & 20,62 & 3,19 & 5,17 & 7,05 & 9,08 \\
\hline Cinzas & 0,59 & 4,60 & 4,52 & 0,98 & 1,31 & 1,69 & 2,09 \\
\hline Fibra bruta & 0,65 & 6,56 & 4,48 & 1,05 & 1,37 & 1,77 & 2,15 \\
\hline Carboidratos $^{(1)}$ & 84,45 & 28,17 & 24,48 & 78,70 & 72,86 & 66,65 & 60,24 \\
\hline
\end{tabular}

${ }^{(1)}$ Calculado por diferença (100 - proteína bruta - extrato etéreo - cinzas - fibra bruta). 
À medida que se aumentou o tempo de cozimento, as proteínas foram progressivamente desnaturadas. Conforme Leitão et al. (1989) e Ormenese et al. (1998), a formação de um retículo protéico mais compacto pode reter melhor o amido e outros nutrientes no produto, proporcionando, assim, menores perdas de sólidos solúveis na água de cozimento.

Tabela 2. Tempo ótimo de cozimento ( $\mathrm{min}$ ) obtido no teste de ordenação pela preferência das massas de trigo e soja pré-cozidas por extrusão em diferentes níveis de umidade e temperaturas de barril $(\mathrm{TB})^{(1)}$.

\begin{tabular}{lcrrrr}
\hline $\begin{array}{l}\text { Proporção } \\
\text { trigo:soja }\end{array}$ & $\begin{array}{c}\text { Umidade } \\
(\%)\end{array}$ & \multicolumn{4}{c}{ Temperatura de barril $\left({ }^{\circ} \mathrm{C}\right)$} \\
\cline { 3 - 6 } & 70 & 80 & 90 & 100 \\
\hline $90: 10$ & 23 & 10 & 9 & 9 & 9 \\
& 26 & 7 & 7 & 7 & 7 \\
& 29 & 7 & 6 & 6 & 6 \\
\hline $80: 20$ & 26 & 6 & 6 & 6 & 6 \\
& 29 & 6 & 5 & 5 & 5 \\
& 32 & 5 & 4 & 4 & 4 \\
\hline $70: 30$ & 29 & 5 & 5 & 4 & 4 \\
& 32 & 4 & 4 & 3 & 3 \\
& 35 & 3 & 3 & 3 & 3 \\
\hline $60: 40$ & 32 & 4 & 4 & 3 & 3 \\
& 35 & 3 & 3 & 3 & 3 \\
& 38 & 3 & 3 & 3 & 3 \\
\hline
\end{tabular}

(1) Os tempos ótimos de cozimento das massas de trigo das marcas comerciais GCA e GCB foram 13 min e $12 \mathrm{~min}$, respectivamente; a TB da zona 1 foi $50^{\circ} \mathrm{C}$ (constante).
Dexter et al. (1981) constataram que, além da temperatura alta, um conteúdo ligeiramente alto de umidade no espaguete pode, também, aumentar a possibilidade de gelatinização do amido, explicando-se as suas perdas relativamente altas por cozimento prolongado. De acordo com Abecassis et al. (1994), em temperatura de até $70^{\circ} \mathrm{C}$, uma maior hidratação da semolina pode beneficiar o intumescimento, diminuindo as suas perdas por cozimento.

Portanto, sugere-se que a elevação da TB e do nível de umidade possa ter contribuído na desnaturação das proteínas que, por consequiência, pode ter acarretado a insolubilização das proteínas, retendo melhor o amido gelatinizado na massa, diminuindo, assim, as perdas de sólidos solúveis no tempo ótimo de cozimento. Entretanto, com a elevação contínua da TB, especialmente em níveis mais altos de umidade, pode ter ocorrido a degradação tanto da proteína como do amido, acelerando as perdas. Acredita-se, também, que o aumento da proporção de soja nas massas pré-cozidas justifique as maiores perdas de sólidos solúveis.

Um elevação na TB do extrusor reduziu o aumento de peso e volume no tempo ótimo de cozimento das massas de trigo e soja pré-cozidas por extrusão até um valor mínimo, além do qual, houve um aumento (Tabelas 4 e 5). Porém, na proporção de $10 \%$ de soja, o me-

Tabela 3. Perdas de sólidos solúveis (\%) no tempo ótimo de cozimento das massas pré-cozidas preparadas com trigo e soja em diferentes proporções e extrusadas em diferentes níveis de umidade e temperaturas de barril (TB) ${ }^{(1)}$.

\begin{tabular}{|c|c|c|c|c|c|c|c|c|}
\hline \multirow[t]{2}{*}{ Identificação da massa pré-cozida } & \multirow[t]{2}{*}{ Proporção trigo:soja } & \multirow[t]{2}{*}{ Umidade $(\%)$} & \multicolumn{4}{|c|}{ Temperatura de barril $\left({ }^{\circ} \mathrm{C}\right)$} & \multirow[t]{2}{*}{ DMS } & \multirow{2}{*}{$\begin{array}{l}\mathrm{CV} \\
(\%)\end{array}$} \\
\hline & & & 70 & 80 & 90 & 100 & & \\
\hline \multirow[t]{3}{*}{ GI } & $90: 10$ & 23 & $5,87 \mathrm{Aa}$ & $5,08 \mathrm{Ba}$ & $5,14 \mathrm{Bb}$ & $5,23 \mathrm{Bc}$ & 0,46 & 2,89 \\
\hline & & 26 & $5,56 \mathrm{Bab}$ & $3,48 \mathrm{Cb}$ & $5,53 \mathrm{Bab}$ & $7,07 \mathrm{Ab}$ & 0,46 & 2,89 \\
\hline & & 29 & $5,28 \mathrm{Bb}$ & $3,38 \mathrm{Cb}$ & $5,68 \mathrm{Ba}$ & 7,81Aa & 0,46 & 2,89 \\
\hline DMS & & & 0,42 & 0,42 & 0,42 & 0,42 & - & - \\
\hline $\mathrm{CV}(\%)$ & & & 2,89 & 2,89 & 2,89 & 2,89 & - & - \\
\hline \multirow[t]{3}{*}{ GII } & $80: 20$ & 26 & 7,71Aa & $6,55 \mathrm{Ba}$ & $5,91 \mathrm{Ca}$ & $6,42 \mathrm{Bb}$ & 0,43 & 2,43 \\
\hline & & 29 & $6,59 \mathrm{Ab}$ & $5,06 \mathrm{Bb}$ & $4,14 \mathrm{Cb}$ & $6,83 \mathrm{Aa}$ & 0,43 & 2,43 \\
\hline & & 32 & $5,79 \mathrm{Bc}$ & $4,74 \mathrm{Cb}$ & $4,10 \mathrm{Db}$ & 7,02Aa & 0,43 & 2,43 \\
\hline$\overline{\mathrm{DMS}}$ & & & 0,38 & 0,38 & 0,38 & 0,38 & - & - \\
\hline $\mathrm{CV}(\%)$ & & & 2,43 & 2,43 & 2,43 & 2,43 & - & - \\
\hline \multirow[t]{3}{*}{ GIII } & $70: 30$ & 29 & 8,96Aa & $8,62 \mathrm{Aa}$ & $5,93 \mathrm{Cb}$ & $7,12 \mathrm{Bc}$ & 0,43 & 2,06 \\
\hline & & 32 & $7,56 \mathrm{Ab}$ & $6,75 \mathrm{Bb}$ & $5,08 \mathrm{Cc}$ & 7,64Ab & 0,43 & 2,06 \\
\hline & & 35 & $6,35 \mathrm{Bc}$ & $5,31 \mathrm{Cc}$ & 7,92Aa & $8,35 \mathrm{Aa}$ & 0,43 & 2,06 \\
\hline DMS & & & 0,39 & 0,39 & 0,39 & 0,39 & - & - \\
\hline $\mathrm{CV}(\%)$ & & & 2,06 & 2,06 & 2,06 & 2,06 & - & - \\
\hline \multirow[t]{3}{*}{ GIV } & $60: 40$ & 32 & 8,76Aa & $8,47 \mathrm{Aa}$ & $6,59 \mathrm{Cb}$ & $7,37 \mathrm{Bb}$ & 0,38 & 1,75 \\
\hline & & 35 & $7,32 \mathrm{Ab}$ & $6,60 \mathrm{Bb}$ & $5,71 \mathrm{Cc}$ & 7,59Ab & 0,38 & 1,75 \\
\hline & & 38 & $7,27 \mathrm{Cb}$ & $5,77 \mathrm{Dc}$ & $8,10 \mathrm{Ba}$ & 8,98Aa & 0,38 & 1,75 \\
\hline DMS & & & 0,34 & 0,34 & 0,34 & 0,34 & - & - \\
\hline $\mathrm{CV}(\%)$ & & & 1,75 & 1,75 & 1,75 & 1,75 & - & - \\
\hline
\end{tabular}


Tabela 4. Aumento de peso $(\mathrm{g} / 100 \mathrm{~g})$ no tempo ótimo de cozimento das massas pré-cozidas preparadas com trigo e soja em diferentes proporções e extrusadas em diferentes níveis de umidade e temperaturas de barril (TB) ${ }^{(1)}$.

\begin{tabular}{|c|c|c|c|c|c|c|c|c|}
\hline \multirow[t]{2}{*}{ Identificação da massa pré-cozida } & \multirow[t]{2}{*}{ Proporção trigo:soja } & \multirow[t]{2}{*}{ Umidade $(\%)$} & \multicolumn{4}{|c|}{ Temperatura de barril $\left({ }^{\circ} \mathrm{C}\right)$} & \multirow[t]{2}{*}{ DMS } & \multirow{2}{*}{$\begin{array}{l}\text { CV } \\
(\%)\end{array}$} \\
\hline & & & 70 & 80 & 90 & 100 & & \\
\hline \multirow[t]{3}{*}{$\overline{\mathrm{GI}}$} & $90: 10$ & 23 & $184,84 \mathrm{Aa}$ & $156,73 \mathrm{Ca}$ & $161,04 \mathrm{BCa}$ & $165,76 \mathrm{Ba}$ & 5,94 & 1,26 \\
\hline & & 26 & $175,34 \mathrm{Ab}$ & $146,40 \mathrm{Cb}$ & $148,00 \mathrm{Cb}$ & $165,57 \mathrm{Ba}$ & 5,93 & 1,26 \\
\hline & & 29 & $159,11 \mathrm{Bc}$ & $126,28 \mathrm{Dc}$ & $145,84 \mathrm{Cb}$ & $165,57 \mathrm{Aa}$ & 5,93 & 1,26 \\
\hline DMS & & & 5,33 & 5,33 & 5,33 & 5,33 & - & - \\
\hline $\mathrm{CV}(\%)$ & & & 1,26 & 1,26 & 1,26 & 1,26 & - & - \\
\hline \multirow[t]{3}{*}{ GII } & $80: 20$ & 26 & $173,52 \mathrm{Aa}$ & $145,43 \mathrm{Ba}$ & $125,41 \mathrm{Ca}$ & $144,55 \mathrm{Ba}$ & 2,20 & 0,54 \\
\hline & & 29 & $166,25 \mathrm{Ab}$ & $139,90 \mathrm{Bb}$ & $110,29 \mathrm{Db}$ & $135,46 \mathrm{Cb}$ & 2,20 & 0,54 \\
\hline & & 32 & $159,98 \mathrm{Ac}$ & $127,12 \mathrm{Bc}$ & $101,58 \mathrm{Cc}$ & $128,85 \mathrm{Bc}$ & 2,20 & 0,54 \\
\hline$\overline{\mathrm{DMS}}$ & & & 1,98 & 1,98 & 1,98 & 1,98 & - & - \\
\hline $\mathrm{CV}(\%)$ & & & 0,54 & 0,54 & 0,54 & 0,54 & - & - \\
\hline \multirow[t]{3}{*}{ GIII } & $70: 30$ & 29 & $166,90 \mathrm{Aa}$ & $139,64 \mathrm{Ba}$ & $103,46 \mathrm{Da}$ & $120,58 \mathrm{Ca}$ & 2,90 & 0,83 \\
\hline & & 32 & $147,03 \mathrm{Ab}$ & $124,30 \mathrm{Bb}$ & $97,24 \mathrm{Db}$ & $104,89 \mathrm{Cb}$ & 2,90 & 0,83 \\
\hline & & 35 & $126,41 \mathrm{Ac}$ & $100,93 \mathrm{Bc}$ & $90,77 \mathrm{Cc}$ & $91,59 \mathrm{Cc}$ & 2,90 & 0,83 \\
\hline DMS & & & 2,60 & 2,60 & 2,60 & 2,60 & - & - \\
\hline CV (\%) & & & 0,83 & 0,83 & 0,83 & 0,83 & - & - \\
\hline \multirow[t]{3}{*}{$\overline{\text { GIV }}$} & $60: 40$ & 32 & $140,43 \mathrm{Aa}$ & $120,52 \mathrm{Ba}$ & $97,93 \mathrm{Da}$ & $102,10 \mathrm{Ca}$ & 3,78 & 1,21 \\
\hline & & 35 & $124,52 \mathrm{Ab}$ & $98,44 \mathrm{Bb}$ & $90,81 \mathrm{Cb}$ & $91,85 \mathrm{Cb}$ & 3,78 & 1,21 \\
\hline & & 38 & $120,66 \mathrm{Ac}$ & $98,88 \mathrm{Bb}$ & $87,80 \mathrm{Cb}$ & $90,73 \mathrm{Cb}$ & 3,78 & 1,21 \\
\hline DMS & & & 3,40 & 3,40 & 3,40 & 3,40 & - & - \\
\hline $\mathrm{CV}(\%)$ & & & 1,21 & 1,21 & 1,21 & 1,21 & - & - \\
\hline
\end{tabular}

${ }^{(1)}$ Médias seguidas pelas mesmas letras, minúscula nas colunas e maiúscula nas linhas, não diferem entre si pelo teste de Tukey a 5\% de probabilidade; a TB da zona 1 foi $50^{\circ} \mathrm{C}$ (constante); o aumento de peso por cozimento das massas de trigo das marcas comerciais GCA e GCB foi 183,70 e $161,36 \mathrm{~g} / 100 \mathrm{~g}$, respectivamente.

Tabela 5. Aumento de volume $\left(\mathrm{cm}^{3} / 100 \mathrm{~g}\right)$ no tempo ótimo de cozimento das massas pré-cozidas preparadas com trigo e soja em diferentes proporções e extrusadas em diferentes níveis de umidade e temperaturas de barril (TB $)^{(1)}$.

\begin{tabular}{|c|c|c|c|c|c|c|c|c|}
\hline \multirow[t]{2}{*}{ Identificação da massa pré-cozida } & \multirow[t]{2}{*}{ Proporção trigo:soja } & \multirow[t]{2}{*}{ Umidade $(\%)$} & \multicolumn{4}{|c|}{ Temperatura de barril $\left({ }^{\circ} \mathrm{C}\right)$} & \multirow[t]{2}{*}{ DMS } & \multirow{2}{*}{$\begin{array}{l}\mathrm{CV} \\
(\%)\end{array}$} \\
\hline & & & 70 & 80 & 90 & 100 & & \\
\hline \multirow[t]{3}{*}{ GI } & $90: 10$ & 23 & $278,75 \mathrm{Aa}$ & $270,83 \mathrm{Ba}$ & $245,45 \mathrm{Da}$ & $250,00 \mathrm{Ca}$ & 4,42 & 0,58 \\
\hline & & 26 & $270,83 \mathrm{Ab}$ & $264,54 \mathrm{Bb}$ & $244,44 \mathrm{Ca}$ & $245,00 \mathrm{Cb}$ & 4,42 & 0,58 \\
\hline & & 29 & $270,83 \mathrm{Ab}$ & $262,50 \mathrm{Bb}$ & $224,54 \mathrm{Db}$ & $237,50 \mathrm{Cc}$ & 4,42 & 0,58 \\
\hline DMS & & & 3,98 & 3,98 & 3,98 & 3,98 & - & - \\
\hline $\mathrm{CV}(\%)$ & & & 0,58 & 0,58 & 0,58 & 0,58 & - & - \\
\hline \multirow[t]{3}{*}{ GII } & $80: 20$ & 26 & $278,63 \mathrm{Aa}$ & $270,00 \mathrm{Ba}$ & $237,50 \mathrm{Da}$ & $245,00 \mathrm{Ca}$ & 5,11 & 0,69 \\
\hline & & 29 & $275,60 \mathrm{Aa}$ & $262,50 \mathrm{Bb}$ & $233,33 \mathrm{Da}$ & $240,00 \mathrm{Cb}$ & 5,11 & 0,69 \\
\hline & & 32 & $270,00 \mathrm{Ab}$ & $251,25 \mathrm{Bc}$ & $222,22 \mathrm{Cb}$ & $227,27 \mathrm{Cc}$ & 5,11 & 0,69 \\
\hline$\overline{\mathrm{DMS}}$ & & & 4,59 & 4,59 & 4,59 & 4,59 & - & - \\
\hline $\mathrm{CV}(\%)$ & & & 0,69 & 0,69 & 0,69 & 0,69 & - & - \\
\hline \multirow[t]{3}{*}{ GIII } & $70: 30$ & 29 & $273,89 \mathrm{Aa}$ & $266,67 \mathrm{Ba}$ & $216,66 \mathrm{Ca}$ & $220,00 \mathrm{Ca}$ & 5,44 & 0,82 \\
\hline & & 32 & $264,16 \mathrm{Ab}$ & $255,55 \mathrm{Bb}$ & $200,69 \mathrm{Cb}$ & $205,11 \mathrm{Cb}$ & 5,44 & 0,82 \\
\hline & & 35 & $225,00 \mathrm{Ac}$ & $205,11 \mathrm{Bc}$ & $166,67 \mathrm{Dc}$ & $172,22 \mathrm{Cc}$ & 5,44 & 0,82 \\
\hline$\overline{\mathrm{DM} \mathrm{S}}$ & & & 4,89 & 4,89 & 4,89 & 4,89 & - & - \\
\hline CV (\%) & & & 0,82 & 0,82 & 0,82 & 0,82 & - & - \\
\hline \multirow[t]{3}{*}{ GIV } & $60: 40$ & 32 & $250,00 \mathrm{Aa}$ & $200,00 \mathrm{Ba}$ & $169,70 \mathrm{Ca}$ & $172,73 \mathrm{Ca}$ & 4,99 & 0,93 \\
\hline & & 35 & $180,00 \mathrm{Ab}$ & $172,72 \mathrm{Bb}$ & $166,67 \mathrm{Ca}$ & $170,83 \mathrm{BCa}$ & 4,99 & 0,93 \\
\hline & & 38 & $172,73 \mathrm{Ac}$ & $172,73 \mathrm{Ab}$ & $166,67 \mathrm{Ba}$ & $169,70 \mathrm{ABa}$ & 4,99 & 0,93 \\
\hline$\overline{\mathrm{DMS}}$ & & & 4,48 & 4,48 & 4,48 & 4,48 & - & - \\
\hline CV $(\%)$ & & & 0,93 & 0,93 & 0,93 & 0,93 & - & - \\
\hline
\end{tabular}

${ }^{(1)}$ Médias seguidas pelas mesmas letras, minúscula nas colunas e maiúscula nas linhas, não diferem entre si pelo teste de Tukey a $5 \%$ de probabilidade; a TB da zona 1 foi $50^{\circ} \mathrm{C}$ (constante); o aumento de volume por cozimento das massas de trigo das marcas comerciais GCA e GCB foi 294,44 e $263,89 \mathrm{~cm}^{3} / 100 \mathrm{~g}$, respectivamente. 
nor aumento de peso ocorreu na TB de $80^{\circ} \mathrm{C}$. Já quanto ao aumento de volume, este mínimo foi na TB de $90^{\circ} \mathrm{C}$. Também ocorreu uma redução do peso e volume no tempo ótimo de cozimento com a elevação do nível de umidade e da proporção de soja.

Dexter \& Matsuo (1979), Edwards et al. (1993) e Grant et al. (1993) constataram que o peso da massa cozida aumentou com o tempo de cozimento. No entanto, Morad et al. (1980) e Taha (1992) verificaram que a suplementação de soja a partir de $2 \%$ resultou em menor peso e volume da massa pré-cozida.

Desta forma, acredita-se que o menor peso e volume encontrado no presente trabalho possa ser explicado, em parte, pela diminuição do tempo ótimo de cozimento e pelo aumento da proporção de soja nas massas précozidas. Também, em níveis mais altos de umidade, o amido pré-gelatinizado e as proteínas desnaturadas das massas pré-cozidas podem ter sido degradados, em virtude do calor mais intenso no extrusor, perdendo, assim, a capacidade de intumescimento e, conseqüentemente, diminuindo o aumento de peso e de volume dos mesmos. Quanto ao incremento observado no peso e volume no tempo ótimo de cozimento com a elevação da TB, acredita-se que seja por causa da formação dos produtos resultantes da reação de Maillard, retendo a água de cozimento e aumentando assim o peso e o volume das massas pré-cozidas.

Comparando-se as massas de trigo e soja pré-cozidas por extrusão do presente trabalho com aquelas de trigo de marcas comerciais GCA e GCB, verifica-se que os tempos ótimos de cozimento de todas as massas pré-cozidas foram menores do que aqueles das massas de marcas comerciais (Tabela 2). As perdas de sólidos solúveis no tempo ótimo de cozimento das massas précozidas obtidas em suas melhores TB, nas quais ocorreram menos perdas, foram comparáveis com aquelas das massas de marcas comerciais, exceto da massa précozida com $40 \%$ de soja submetida anteriormente a TB de $90^{\circ} \mathrm{C}$ e $32 \%$ de umidade (Tabela 3 ). As massas précozidas foram inferiores quanto ao peso e volume em relação à massa da marca comercial GCA, mas comparáveis com o da marca comercial GCB na proporção de $10 \%$ de soja (Tabelas 4 e 5).

\section{Conclusões}

1. O tempo ótimo de cozimento de massas de trigo e soja pré-cozidas por extrusão diminui com o aumento da temperatura de barril, do nível de umidade e da proporção de soja.

2. O aumento da proporção de soja resulta num aumento das perdas de sólidos solúveis no tempo ótimo de cozimento das massas de trigo e soja pré-cozidas por extrusão.

3. O aumento na temperatura de barril do extrusor causa uma diminuição do peso e volume no tempo ótimo de cozimento das massas de trigo e soja pré-cozidas por extrusão.

\section{Referências}

ABECASSIS, J.; ABBOU, R.; CHAURAND, M.; MOREL, M.H.; VERNOUX, P. Influence of extrusion conditions on extrusion speed, temperature, and pressure in extruder and on pasta quality. Cereal Chemistry, v.71, p.247-253, 1994.

AMERICAN ASSOCIATION OF CEREAL CHEMISTS (St. Paul, Estados Unidos). Approved methods of the American Association of Cereal Chemists. ${ }^{\text {th }}$ ed. St. Paul, 1995. $2 \mathrm{v}$.

CABALLERO-CÓRDOBA, G.M.; WANG, S.-H.; SGARBIERI, V.C. Características nutricionais e sensoriais de sopa cremosa semiinstantânea à base de farinhas de trigo e soja desengordurada. Pesquisa Agropecuária Brasileira, v.29, p.1137-1143, 1994.

CHEFTEL, J.C.; CUQ, J.L.; LORIENT, D. Proteínas alimentarias. Zaragoza: Acribia, 1989. 346p.

CHEN, J.; SERAFIN, F.L.; PANDYA, R.N.; DAUN, H. Effects of extrusion conditions on sensory properties of corn meal extrudates. Journal of Food Science, v.56, p.84-89, 1991.

DE STEFANIS, E.; SGRULLETTA, D. Effects of high-temperature drying on technological properties of pasta. Journal of Cereal Science, v.12, p.97-104, 1990.

DEXTER, J.E.; MATSUO, R.R. Changes in spaghetti protein solubility during cooking. Cereal Chemistry, v.56, p.394-398, 1979.

DEXTER, J.E.; MATSUO, R.R.; MORGAN, B.C. High temperature drying: effect on spaghetti properties. Journal of Food Science, v.46, p.1741-1746, 1981.

EDWARDS, N.M.; IZYDORCZYK, M.S.; DEXTER, J.E.; BILIADERIS, C.G. Cooked pasta texture: comparision of dynamic viscoelastic properties. Cereal Chemistry, v.70, p.122-126, 1993.

FERNANDES, M.S.; WANG, S.-H.; ASCHERI, J.L.R.; OLIVEIRA, M.F.; COSTA, S.A.J. Produtos extrusados expandidos de misturas de canjiquinha e soja para uso como petiscos. Pesquisa Agropecuária Brasileira, v.37, p.1495-1501, 2002.

GONZALEZ-AGRAMON, M.; SERNA-SALDIVAR, S.O. Effect of defatted soybean and soybean isolate fortification on the nutritional, physical, chemical and sensory properties of wheat flour tortillas. Journal of Food Science, v.53, p.793-797, 1988. 
GRANT, L.A.; DICK, J.W.; SHELTON, D.R. Effects of drying temperature, starch damage, sprouting, and additives on spaghetti quality characteristics. Cereal Chemistry, v.70, p.676-684, 1993.

HORVÁTH, E.; PETRES, J.; GELENCSÉR, É.; CZUKOR, B. Effect of extrusion temperature on physico-chemical properties and biological value of soybean-protein. Acta Alimentaria, v.18, p.199$211,1989$.

KAHAN, G.; COOPER, D.; PAPAVISILIOU, A.; KRAMER, A. Expanded tables for determining significance of differences for ranked data. Food Technology, v.27, p.61-69, 1973.

KAMER, J.H. van de; GINKEL, L. van. Rapid determination of crude fiber in cereals. Cereal Chemistry, v.29, p.239-251, 1952.

KRUGER, J.E.; ANDERSON, M.H.; DEXTER, J.E. Effect of flour refinement on raw cantonese noodle color and texture. Cereal Chemistry, v.71, p.177-182, 1994.

LEITÃO, R.F.F.; GONÇALVES, J.R.; VITTI, P. Utilização da alta temperatura na secagem de macarrão. Coletânea ITAL, v.19, p.186$195,1989$.
MORAD, M.M.; EL-MOGOLI, S.B.; AFIFI, S.A. Macaroni supplemented with lupin and defatted soybean flours. Journal of Food Science, v.45, p.404-405, 1980.

ORMENESE, R.C.S.C.; LEITÃO, R.F.F.; SILVEIRA, N.F.A.; BALDINI, V.L.S. Influência da secagem à alta temperatura nas características das massas com ovos. Ciência e Tecnologia de Alimentos, v.18, p.7-12, 1998.

PIMENTEL-GOMES, F. Curso de estatística experimental. 13.ed. São Paulo: Nobel, 1991. 468p.

TAHA, S.A. Biochemical, rheological, cooking quality and acceptability of defatted soy-supplemented whole durum meal noodles. Acta Alimentaria, v.21, p.229-238, 1992.

WANG, S.-H.; BORGES, G.G.; CABRAL, L.C.; ARAÚJO, F.B. Efeito da proporção canjiquinha:soja na solubilidade, dispersibilidade e propriedades emulsificantes de mingaus desidratados. Pesquisa Agropecuária Brasileira, v.36, p.357-362, 2001. 